\title{
Badania połączeń elektrotechnicznych lutowanych na miękko
}

\section{Study of soldered electrotechnical joints}

\section{Streszczenie}

Przedmiotem badań były złącza elektrotechniczne przewodów miedzianych do miedzianej ścieżki płytki obwodu drukowanego lutowanych lutem miękkim bezołowiowym na osnowie cyny.

Zakres badań obejmował określenie wytrzymałości złączy lutowanych na ścinanie przy siłach rozciągających złącze oraz wykonanie badań makro- i mikroskopowych.

\section{Badania złączy}

Zgodnie z unijną dyrektywą RoHS producenci elektroniki i urządzeń elektrotechnicznych zobowiązani są do stosowania lutów niezawierających substancji niebezpiecznych, w tym ołowiu Pb [1]. Warunki te spełniaja dwuskładnikowe stopy $\mathrm{Sn}-\mathrm{Cu}, \mathrm{Sn}-\mathrm{Ag}$ oraz trójskładnikowe $\mathrm{Sn}-\mathrm{Ag}-\mathrm{Cu}$ zwane powszechnie lutami SAC.

Bezołowiowe, ekologiczne luty, które spełniają dyrektywę RoHS, zapewniają równie dobre połączenia między lutowanymi elementami jak luty $\mathrm{Sn}-\mathrm{Pb}$, jednak mają wyższą o ok. $50^{\circ} \mathrm{C}$ temperaturę topnienia. Stopy bezołowiowe uważa się za luty o gorszej zwilżalności niż luty $\mathrm{Sn}-\mathrm{Pb}$, lecz złącza nimi lutowane osiągają wyższe właściwości wytrzymałościowe [2].

Złącza do badań wykonano przy użyciu lutu S-Sn96,5Ag3Cu0,5 (SAC 305) o temperaturze topnienia $217 \div 219^{\circ} \mathrm{C}$, w postaci drutu rdzeniowego o średnicy $0,7 \mathrm{~mm} \mathrm{z}$ topnikiem 1.1.3 B o zawartości 3\% [3].

Prof. dr hab. inż. Andrzej Ambroziak, dr inż. Piotr Białucki, dr inż. Wiesław Derlukiewicz, dr inż. Artur Lange, dr inż. Leszek Łatka - Politechnika Wrocławska.

\section{Abstract}

The electrotechnical soldered joints of copper wires to copper track printed circuit board were the object of investigations.

The scope of research included determining the shear strength of soldered joints and macro- and microscopic investigations.
Tablica I. Skład chemiczny lutu S-Sn96,5Ag3Cu0,5 wg PN-EN ISO 9453:2006 [4], \% wag.

Table I. The chemical composition of the S-Sn965Ag3Cu0,5 solder, acc. to PN-EN ISO 9453:2006 [4], \% mas.

\begin{tabular}{|c|c|c|c|c|c|c|c|c|c|c|c|}
\hline Sn & $\mathrm{Ag}$ & $\mathrm{Cu}$ & $\mathrm{Pb}$ & $\mathrm{Cd}$ & $\mathrm{Sb}$ & $\mathrm{Bi}$ & $\mathrm{Fe}$ & $\mathrm{Zn}$ & $\mathrm{Al}$ & As & Inne \\
\hline $\begin{array}{l}\mathbb{J} \\
N \\
\Phi \\
\Phi\end{array}$ & $\stackrel{\circ}{m^{\circ}}$ & $\begin{array}{l}10 \\
0 \\
0\end{array}$ & $\begin{array}{l}20 \\
0\end{array}$ & $\begin{array}{l}\text { 尺े } \\
\text { o } \\
0\end{array}$ & $\frac{0}{0}$ & $\frac{0}{0}$ & & $\begin{array}{l}8 \\
8 \\
0\end{array}$ & $\begin{array}{l}5 \\
8 \\
0\end{array}$ & O̊ & 0 \\
\hline
\end{tabular}

Zawartość pierwiastków stopowych w lucie SAC 305 przedstawiono $w$ tablicy I, a wygląd badanych złączy na rysunku 1.

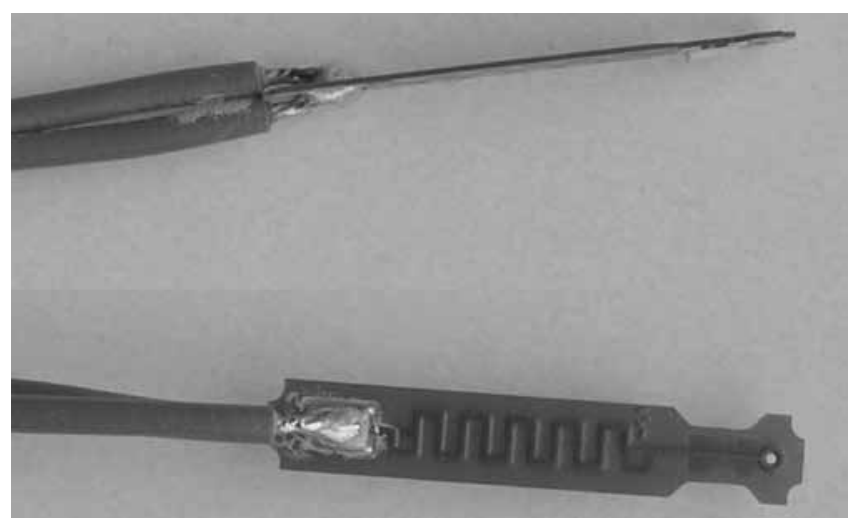

Rys. 1. Złącza lutowane przeznaczone do badań wytrzymałościowych i metalograficznych

Fig. 1. Soldered joints intended for strength tests and metallographic investigations 


\section{Badania wytrzymałości na ścinanie połączeń lutowanych}

Połączenia drucików elektrycznego przewodu miedzianego tworzą ze ścieżką miedzianą na płytce drukowanej złącze zakładkowe. Ten rodzaj złącza projektuje się do przenoszenia naprężeń ścinających. Wytrzymałość na ścinanie złączy lutowanych na miękko określano na podstawie próby rozciągania.

Płytka drukowana złącza lutowanego jest bardzo cienka i ma małą powierzchnię, w związku z czym nie można jej bezpośrednio zamocować w szczękach maszyny wytrzymałościowej. W związku z tym próbki do badań wymagały odpowiedniego przygotowania. Do obu stron płytki drukowanej i przylutowanego przewodu doklejano nakładki aluminiowe o grubości $1 \mathrm{~mm}$, powiększając powierzchnię mocowania próbki w szczękach maszyny wytrzymałościowej.

Próbę ścinania badanych złączy lutowanych przeprowadzono na uniwersalnej maszynie wytrzymałościowej Tinius Olsen H25KT zakresie do $200 \mathrm{~N}$.

Dwa badane złącza po próbie rozciągania pokazano na rysunku 2.

W wyniku przeprowadzonych prób stwierdzono, że wytrzymałość złączy jest większa niż wytrzymałość przewodu miedzianego. Siła niszcząca przewody miedziane złączy mieściła się w przedziale 150 $\div 160 \mathrm{~N}$.

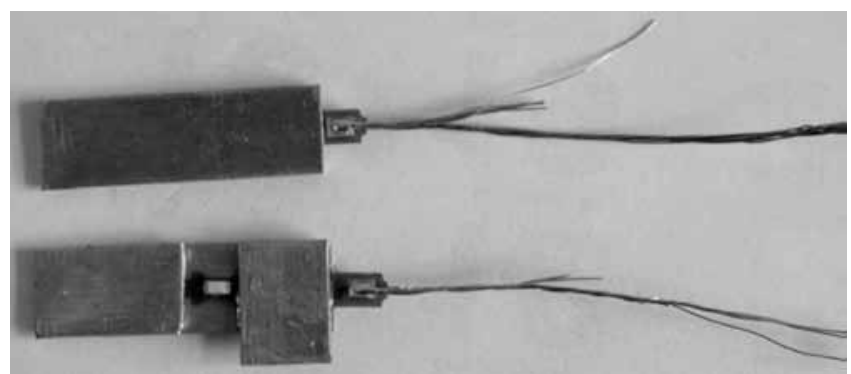

Rys. 2. Próbki złączy lutowanych na miękko po badaniach wytrzymałości na ścinanie

Fig. 2. View of soldered joints after shear tests

\section{Badania metalograficzne}

\section{Badania na mikroskopie świetlnym}

Badania metalograficzne złączy lutowanych wykonano na mikroskopie świetlnym OLYMPUS CK40M oraz na mikroskopie elektronowym TESCAN.

Na rysunkach 3 i 4 pokazano budowę złączy lutowanych na przekrojach poprzecznych, a na rysunkach 5 i 6 na przekroju wzdłużnym.

Obserwacje mikroskopowe złączy lutowanych na zgładach poprzecznych i wzdłużnych wykazały wysoką jakość połączenia miedzianych drucików przewodów ze sobą oraz ze ścieżką miedzianą o grubości $0,07 \mathrm{~mm}$ płytki drukowanej. Przy powierzchniach granicznych między drucikami oraz drucikami i ścieżką miedzianą występują wyraźne, charakterystyczne

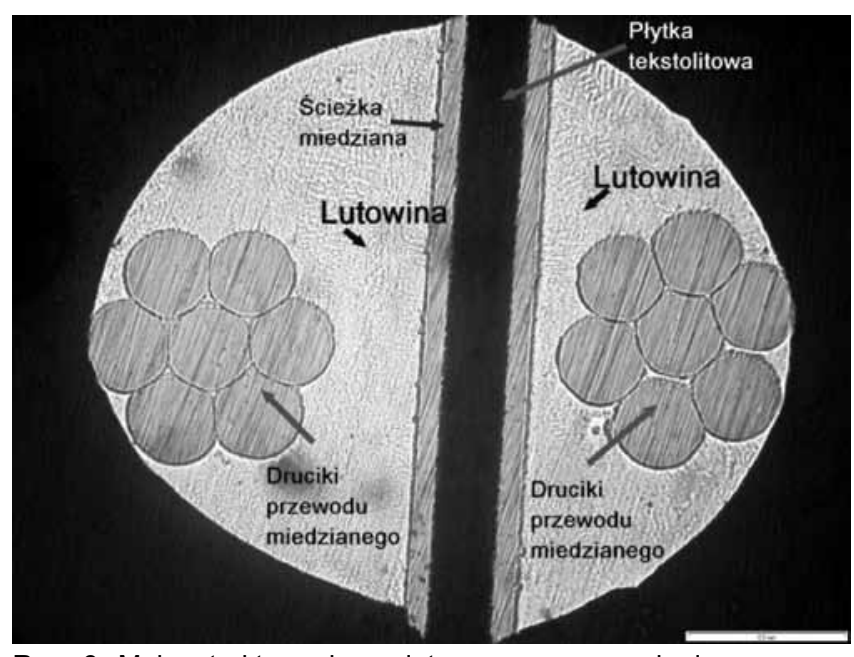

Rys. 3. Makrostruktura złącza lutowanego na przekroju poprzecznym. Zgład nietrawiony. Pow. 50x

Fig. 3. Macrostructure of solder joint on the cross-section. Unetched. Magn. 50x

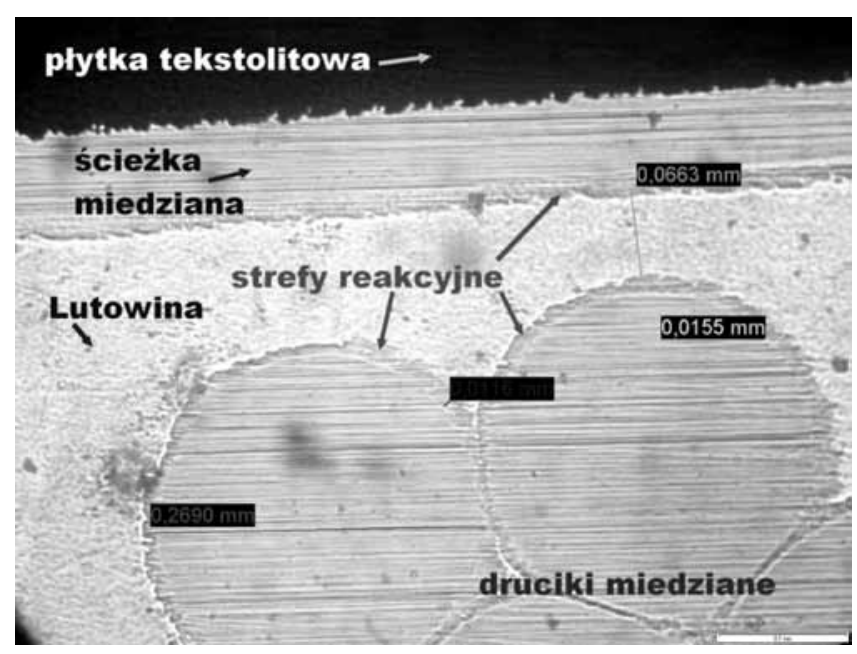

Rys. 4. Mikrostruktura złącza lutowanego na przekroju poprzecznym. Zgład nietrawiony. Pow. 200x

Fig. 4. Microstructure of solder joint on the cross-section. Unetched. Magn. 200x

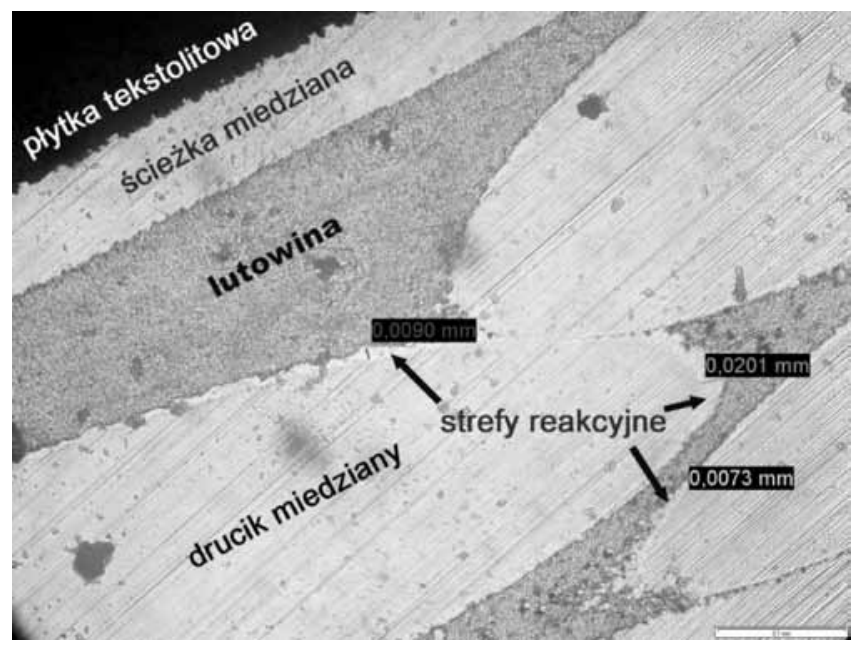

Rys. 5. Mikrostruktura złącza lutowanego na przekroju wzdłużnym. Zgład nietrawiony. Pow. 200x

Fig. 5. Microstructure of solder joint on the longitudinal section. Unetched. Magn. 200x 


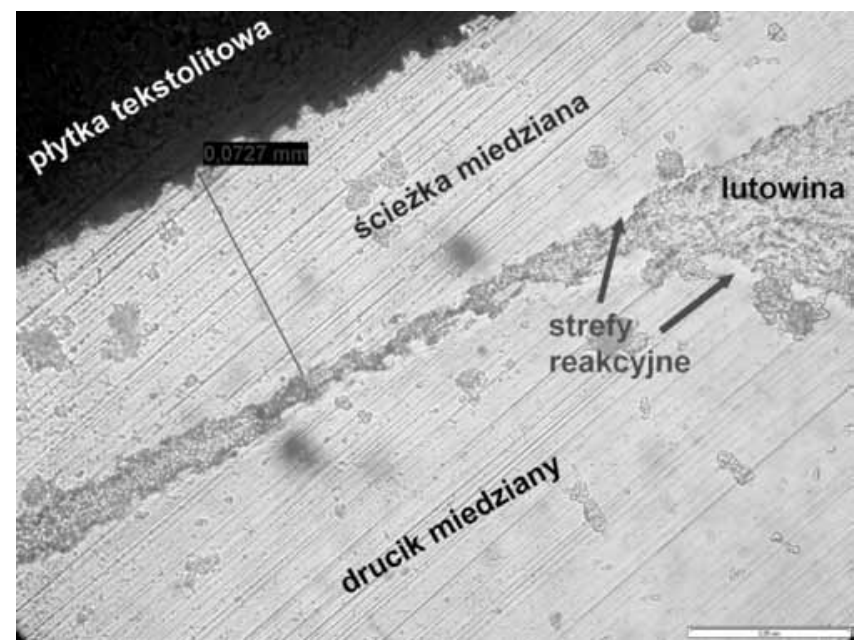

Rys. 6. Mikrostruktura złącza lutowanego na przekroju wzdłużnym. Zgład nietrawiony. Pow. 500x

Fig. 6. Microstructure of solder joint on the longitudinal section. Unetched. Magn. 500x

strefy reakcyjne lutu z miedzią o szerokości kilku, a miejscami kilkunastu mikrometrów, świadczące o wystąpieniu procesów rozpuszczania miedzi w lucie, co jest bardzo ważne dla powstania prawidłowego złącza lutowanego.

\section{Badania metalograficzne na mikroskopie elektronowym skaningowym}

Do badań na elektronowym mikroskopie skaningowym wybrano zgład poprzeczny. Budowę złącza w obszarze obserwowanym przy ścieżce miedzianej pokazano na rysunku 7 . Wykonano również analizę składu chemicznego wzdłuż linii obejmującej drucik

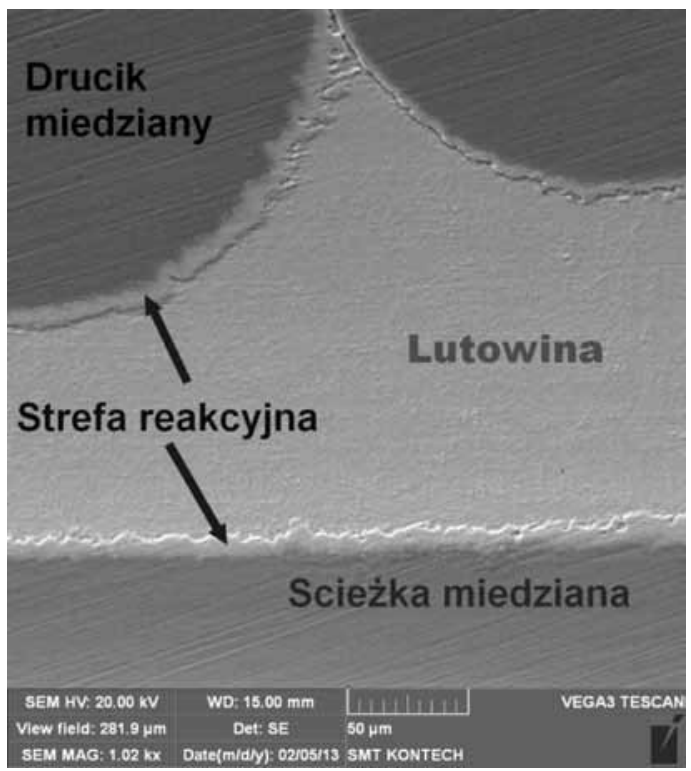

Rys. 7. Mikrofotografia SEM złącza lutowanego na miękko. Zgład nietrawiony. Pow. 1020x

Fig. 7. SEM micrograph of soldered joint. Unetched. Magn. 1020x miedziany, strefę reakcyjną oraz lutowinę (rys. 8), a także skład chemiczny punktowy (średnica plamki $2 \mu \mathrm{m}) \mathrm{w}$ strefie reakcyjnej (rys. 9).

Przedstawione na rysunkach 8 i 9 mikrofotografie z mikroskopu skaningowego potwierdzają prawidłową budowę złącza lutowanego zaobserwowanego wcześniej na mikroskopie świetlnym.

Punktowa analiza w strefie reakcyjnej wskazuje na obecność miedzi, cyny i srebra, co potwierdza wzajemne rozpuszczanie się składników złącza lutowanego i świadczy o jego prawidłowej budowie (rys. 9). $Z$ analizy EDX na rysunku $8 \mathrm{~b}$ widać, że strefa reakcyjna osiąga szerokość nawet $16 \mu \mathrm{m}$.

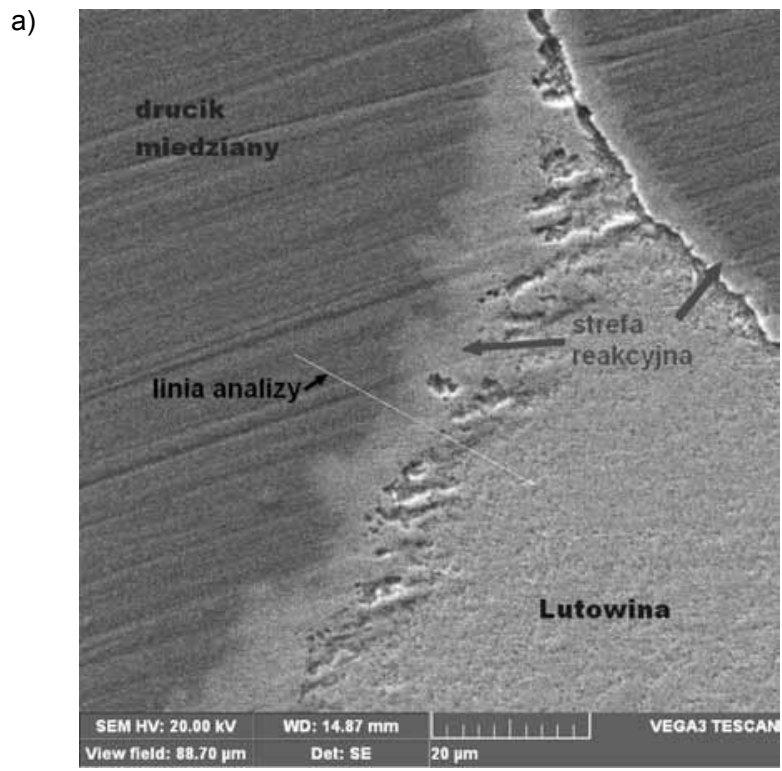

b)

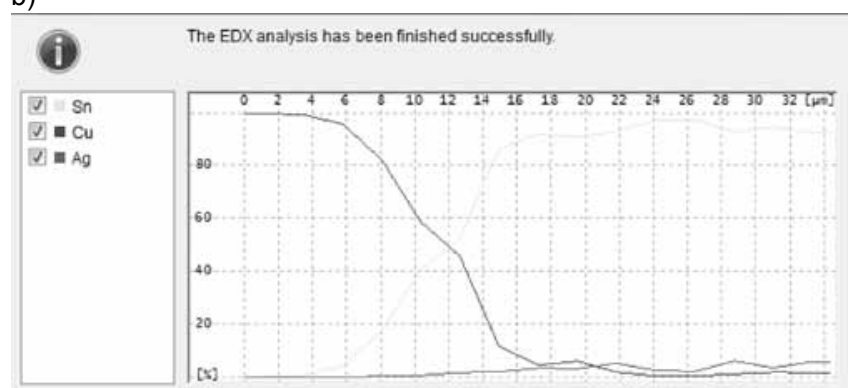

c)

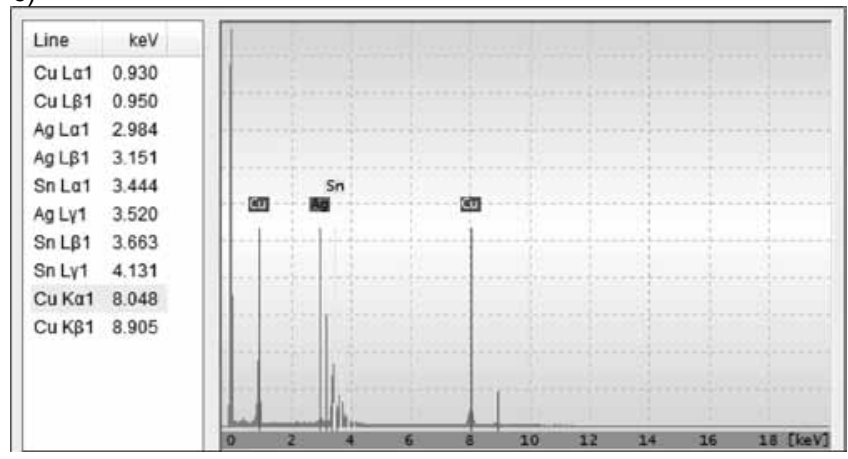

Rys. 8. Mikroanaliza rozkładu pierwiastków wzdłuż linii w pobliżu strefy reakcyjnej: a) SEM obszaru badanego złącza, b) i c) analiza EDX rozkładu pierwiastków

Fig. 8. Microanalysis of the distribution of elements along the line near the reaction zone: a) SEM study area of joint, b) and c) EDX analysis of the distribution of elements 
a)

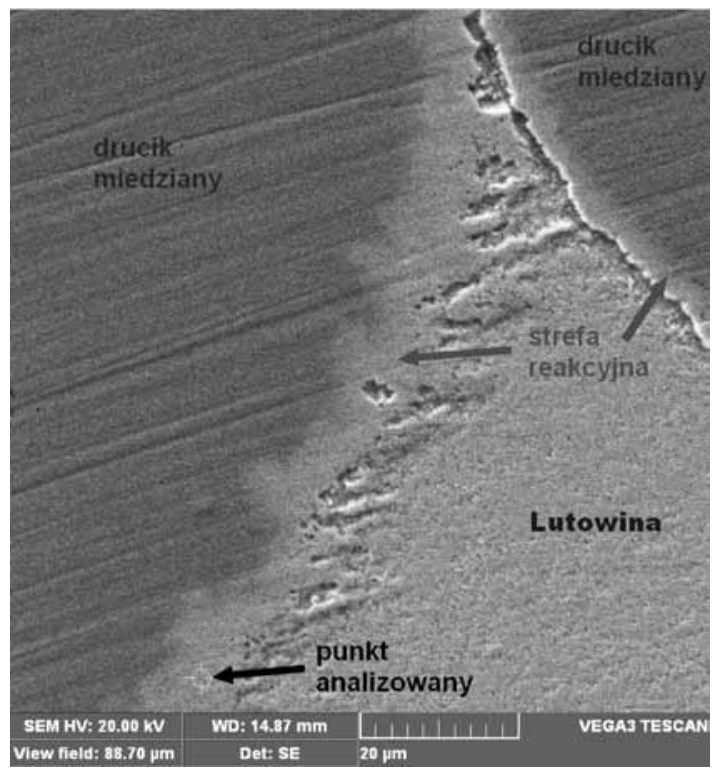

b)

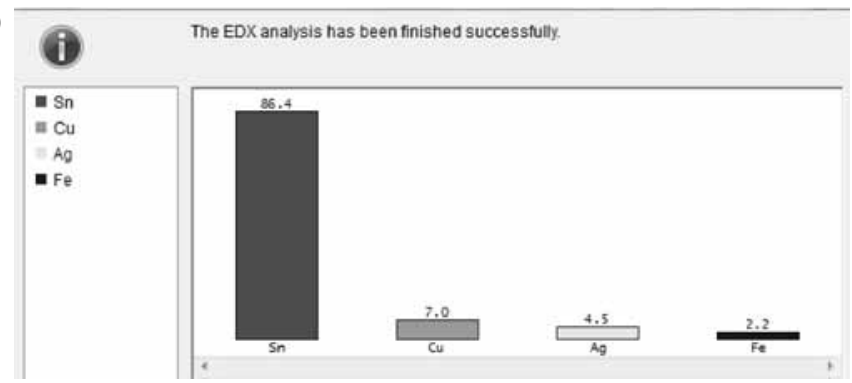

Rys. 9. Punktowa mikroanaliza zawartości pierwiastków w strefie reakcyjnej: a) SEM obszaru badanego złącza, b) analiza EDX rozkładu pierwiastków

Fig. 9. Spot microanalysis of elements in the reaction zone: a) SEM study area of joint, b) EDX analysis of the distribution of elements

\section{Wnioski}

Wyniki próby rozciągania złączy wykazały, że ich wytrzymałość na ścinanie jest większa niż wytrzymałość drucików miedzianych przewodów złącza. Siły niszczące przewody złącza mieściły się w przedziale $150 \div 160 \mathrm{~N}$.

Badania metalograficzne makro- i mikroskopowe wykonane na mikroskopie optycznym wykazały wysoką jakość złączy lutowanych. Pomiędzy lutowiną a powierzchnią elementów złączy widoczne są wyraźnie strefy reakcyjne o szerokości wynoszącej od kilku do kilkunastu mikrometrów.

Mikrofotografie SEM z mikroskopu elektronowego potwierdziły wyniki badań z mikroskopu świetlnego. Analiza EDX wykazała obecność w strefie reakcyjnej składników lutu oraz powiększoną zawartość miedzi pochodzącej z drucików przewodu lub ze ścieżki płytki drukowanej.

\section{Literatura}

[1] http://www.rohs-weee.pl/rohs.php. 2013-05-07.

[2] http://www-old.wemif.pwr.wroc.pl/dydaktyka/etd8022/Montaz w elektronice_cz.12_Lutowanie bezolowiowe.pdf. 2013-05-07.
[3] PN-EN ISO 9454-2:2004 Topniki do lutowania miękkiego - Klasyfikacja i wymagania - Część 2: Wymagania użytkowe.

[4] PN-EN ISO 9453:2006 Luty miękkie -- Skład chemiczny i postać.

\section{Spotkania Spawalników w 2013 r.}

6 Warmińsko-Mazurska Biesiada Spawalnicza Olsztyn, 13.06.2013

Kontakt: Wiesława Bączyk, tel.: 8953510 00, e-mail: olsztyn@rywal.com.pl

II Dolnośląskie Sympozjum Spawalnicze Wrocław, 19.06.2013

Kontakt: Artur Lange, tel.: 7132021 45, Artur.Lange@pwr.wroc.pl

XII Szczecińskie Seminarium Spawalnicze Szczecin, 5.09.2013

Kontakt: Katarzyna Rudzka, tel.: 91462 42 75, Katarzyna.Rudzka@pl.linde-gas.com

II Kieleckie Spotkanie Spawalników Kielce, 12.09.2013

Kontakt: Ewelina Janus, tel.: 4136874 80, Ewelina.Janus@pl.linde-gas.com

XVII Pomorskie Spotkanie Spawalników Gdańsk, 17.10.2013

Kontakt: Iwona Janson, tel.: 5851128 00, Iwona.Janson@pl.linde-gas.com 